\title{
A SAÚDE MENTAL COMO CAMPO DE SABER: POR UM NOVO PARADIGMA NÃO FRAGMENTÁRIO
}

Walter Ferreira de Oliveira ${ }^{1}$

RESUMO: As sociedades modernas organizam-se com base em categorizações, setorializações, divisões do conhecimento e das ações de acordo com áreas específicas de saber. Embora este forma organizativa possa orientar muitas atividades humanas e os saberes em que elas se fundamentam de maneira eficiente, no caso da saúde mental há dificuldades inerentes para a conformação a esta visão fragmentária. Há que buscar novas formas e novas linguagens para promover uma melhor compreensão da psique e da construção de subjetividades na perspectiva de uma construção continuada do campo da saúde mental.

PALAVRAS CHAVE: Saúde mental; Subjetividades; Produção de conheciimento.

\section{O PARADIGMA DA FRAGMENTAÇÃO}

O mundo ocidental parece ter assimilado hegemonicamente, na ciência, 0 legado descartiano e o paradigma pós positivista, e na organização política e econômica a configuração capitalista neoliberal. Nesta perspectiva pauta-se por uma visão de mundo onde disposições fragmentárias permeiam as relações entre os seres humanos e destes com os outros entes da natureza. Esta posição de fragmentação organiza as maneiras de viver e, conseqüentemente, a condição humana temporal, no momento histórico vivido, bem como as configurações sociais e os fenômenos destas decorrentes. Nesta visão cósmica transparece uma maneira particular de como o ser humano compreende seu papel no mundo, o que inclui a idéia de um poder ilimitado que exerce sobre as coisas da natureza e que é utilizado para fins de desenvolvimento dos sistemas organizadores das formas de vida conforme orientadas pelos preceitos vigentes da ordem econômica e

\footnotetext{
${ }^{1}$ Professor titular, Departamento de Saúde Pública, Universidade Federal de Santa Catarina.
} 
social. Os sentidos, significados, objetivos e o destino que o ser humano traça para si se colocam, desta maneira, como resultados desta visão de mundo e da conseqüente escolha de uma determinada maneira de ser.

E como se processam, como se constroem esta visão, estas posições, estes paradigmas, estes modos de vida, estas maneiras de ser? Esta é uma questão viva, que para as ciências humanas torna-se imperativa. As respostas a esta inquisição passam pelo estudo dos conceitos, da elaboração das representações sociais e, em ultima análise, pela construção das identidades subjetivas, grupais, sociais e universais. Neste texto nos limitamos a sugerir a necessidade de discussão de alguns aspectos relativos aos campos do conhecimento e das práticas em saúde mental, com objetivo de contribuir para o avanço das reflexões sobre estes temas, da mais alta relevância para o progresso ${ }^{2}$ da sociedade.

\section{AS IDENTIDADES COMO EXPRESSÕES CULTURAIS}

Os sujeitos, grupos e sociedades se constituem em meio a ambientes culturais (HARRIS, 1990). Somos socializados, desde tenra idade, com base em valores, crenças e comportamentos que nos são legados primeiro no contexto da família ou de grupos substitutos desta, depois na escola ou em ambientes que a substituem, através da convivência com grupos específicos (outras crianças, adolescentes, jovens, grupos de classe) e, já na idade adulta, através do trabalho, associações religiosas e outros ambientes sociais e institucionais. Nestes ambientes a pessoa sofre a influência direta dos guardiães de sua socialização, sejam pais, familiares, professores, amigos, companheiros de trabalho, de lazer, etc., além da influência menos ou mais direta dos poderes de mídia. Valores, crenças, atitudes e comportamentos resultam, em grande parte, dos ensinamentos proporcionados ininterruptamente por estas forças culturais, de forma contínua, como em conversas com pais, sermões de lideres espirituais, ou conteúdos da educação formal ou informal. Há, ainda, a captação sub-reptícia de mensagens através de,propagandas diversas, muitas com interesses corporativos ou

\footnotetext{
${ }^{22}$ Usamos preferencialmente o termo "progresso social" conrapondo-se a "desenvolvimento social"em acordo $\operatorname{com} \ldots$
} 
comerciais. Incorporam-se, no contexto destas interações, de forma consciente ou inconsciente, conceitos inerentes a diversas posições sociais e culturais. Desta forma se constituem os pilares da formação de identidades (OLIVEIRA, 2003).

Assim, com base na incorporação de conceitos, valores, crenças e comportamentos formam-se os sujeitos $e$ as identidades sociais. Estas subjetividades e identidades são, entretanto, fluidas, constantemente sofrendo renovações, sendo cotidinanamente recriadas, transformadas ou consolidadas. Parte importante desta perene construção, nos meios das sociedades ocidentais modernas, é a aculturação que configura papéis sociais como de cidadãos e consumidores. Desta forma, os conceitos, valores, crenças e hábitos se organizam para o fenômeno da constituição identitária em seu determinado momento histórico e no contexto dos territórios de fluxo das atividades sociais.

\section{CAMPOS E CATEGORIAS DE PRÁTICAS E SABERES}

No contexto da criação continuada de identidades subjetivas e grupais há demandas constantes para institucionalização da organização das ações humanas. Para melhor institucionalizar as maneiras de viver é comum que se recorra à categorização. Daí emanam divisões, setores, áreas de atuação, de visão, de qualificação. Esta forma propicia uma atitude básica pautada pela fragmentação de atividades, saberes e poderes, emergindo neste contexto a liderança de entidades, instituições, organizações e outras formas associativas que, por sua vez, e de forma circular, constituem-se de acordo com as fragmentações pelas quais são convocadas. Uma base central para a manutenção desta estrutura é a ordenação institucionalizada da produção, legitimação e difusão do conhecimento, inclusive do denominado conhecimento científico.

O conhecimento, produzido neste formato fragmetnário, é legitimado por instituições a que são atribuídos especificamente tais mandatos. Estas instituições dialogam dinamicamente com as entidades onde se processa, de várias maneiras, o conhecimento denominado científico, como universidades e agencias de exercício da prática. Esta dinâmica não é, entretanto, simétrica, já que as próprias universidades e agencias de praticas são submetidas a avaliações e ingerência 
direta de entidades superiores (Ex.: agencias governamentais) que orientam a difusão e consumo do conhecimento produzido. Assim se organizam os diversos campos de saber, que configuram, como pontua Foucault, territórios de disputas de poder (FOUCAULT, 2007).

No Brasil, duas entidades são as principais responsáveis pela organização dos campos de conhecimento científico. O Conselho Nacional de Desenvolvimento Científico e Tecnológico (CNPq) é uma agência governamental vinculada ao Ministério da Ciência e Tecnologia e que tem como finalidade o fomento da pesquisa científica e tecnológica e o incentivo à formação de pesquisadores no Brasil (CNPq, 2021). E, no âmbito das atividades de pós graduação, a Coordenação de Aperfeiçoamento de Pessoal de Nível Superior (Capes), órgão também de governo, vinculada ao Ministério da Educação e Cultura, tem como objetivo promover a expansão e a consolidação dos cursos de pós-graduação stricto sensu, ou seja, dos cursos de mestrado e doutorado, em todo o país (CAPES, 2017).

CNPq e Capes admitem o campo da saúde como uma grande área de conhecimento. No caso do CNPq, a área da saúde inclui Medicina, Odontologia, Enfermagem, Nutrição, Saúde Coletiva, Fonoaudiologia, Educação Física, Fisioterapia e Terapia Ocupacional. A Psicologia, no CNPq, é uma subárea das Ciências Humanas.

A Capes avalia os cursos de pós gradução no Brasil de acordo com 12 áreas de conhecimento: Biodiversidade, Biotecnologia, Ciência da Computação, Ciências Ambientais, Ciências Biológicas I, Ciências Biológicas III, Ensino Interdisciplinar, Materiais, Medicina Veterinária, Psicologia e Teologia (CAPES, 2017).

Assim, no CNPq a área da Saúde Coletiva se coloca de forma autônoma, mas na Capes é uma subárea da Medicina 2, que por sua vez se situa como uma subárea das Ciências Biológicas. A Psicologia é uma área autônoma da Capes.

SAÚDE MENTAL: O CAMPO DE CONHECIMENTO E PRÁTICAS 
No que se refere à Saúde Mental (SM), estas formas de divisão de áreas suscitam ponderações. O campo da SM é visto, tradicionalmente, como integrado ao campo da Medicina, concepção decorrente da trajetória histórica do campo, focado primordialmente na loucura, posteriormente na doença e, finalmente, no transtorno mental.

A Medicina consolidou-se como profissão a partir de um objeto central, a doença. O médico afirmou-se socialmente como profissional dedicado ao cuidado, tratamento e, por vezes, à investigação da cura das doenças. Sua inserção no campo da saúde mental ocorreu na medida em que a psiquiatria, conforme definida por precursores como Pinel (2007) configurou-se como especialidade médica destinada a tratar, cuidar e estudar as doenças mentais.

Porém, o objeto de um campo que se defina como de Saúde Mental não pode se limitar às doenças mentais, assim como o campo da saúde não pode se limitar ao estudo das doenças. Esse problema já tem sido extensamente examinado, na prática, com a implantação de novos modelos de Sistema de Saúde, de caráter eminentemente transdisciplinares, como é o caso do SUS. A implantação destes novos modelos de sistema, se por um lado potencializou visões multiprofissionais e interdisciplinares sobre os objetos do campo, por outro lado não questionou, ainda, de forma peremptória, a hegemonia da profissão médica na organização, produção, legitimação e difusão de saberes e práticas sobre saúde. Nem no caso do campo da saúde nem do da SM se conseguiu, ainda, fazer uma discussão publica, e nem mesmo no interior dos meios acadêmicos, que examine com profundidade a pertinência da visão eminentemente médica sobre os fenômenos envolvidos com a promoção, proteção e cuidado à saúde e com a prevenção de doenças. Os maiores focos desta discussão ainda se centram no estudo das diferentes racionalidades médicas, mas esta discussão é mitigada pelo lugar em que as correntes hegemônicas colocam o discurso sobre as racionalidades diversas, relacionandoas essencialmente às práticas "integrativas e complementares" (BARBOSA et al, 2020). 
Levanta-se, portanto, a questão, se o campo da Saúde Mental não mais dev se restringir ao das doenças mentais, não mais deve então ser primordialmente território de hegemonia da profissão médica. O campo abrange, para além do conhecimento das doenças que por acaso afetem a mente, outros fenômenos ligados à saúde, à condição mental, aos fenômenos geralmente relacionados àquilo que convencionamos chamar de "mente", embora não tenhamos clareza do que estamos, neste caso, exatamente tratando. E para que possamos atingir um grau maior de clareza sobre o tema, é necessário exatamente que o campo não esteja amarrado a uma interdisciplinaridade hipotética, a uma hegemonia tacitamente aceita como tal.

O campo da SM admite, portanto, dificuldades particulares, para fins de sua alocação em uma área de saber, prática e poder. É, no mínimo, um campo limítrofe entre áreas como Saúde, Ciências Humanas e Ciências Sociais.

\section{RESSIGNIFICANDO A SAÚDE MENTAL: POR UMA LINGUAGEM NÃO FRAGMENTÁRIA}

O entendimento da condição humana passa, hoje, por uma amplitude de conhecimentos que dificulta a resignação do campo da SM ao estilo fragmentário, tão caro e confortável para setores tradicionalmente ligados à produção, organização, distribuição e consumo do conhecimento. Passa pela lingüística, na medida em que a própria consciência de si, a consciência do "eu", é uma construção da linguagem. Pela Arte, elemento fundamental na construção cultural e forma primordial da expressão humana. Pela Antropologia, pela Educação Física, pelas ciências do Direito, pela Neurologia, pela Cibernética e por tantas outras formas de entendimento e práxis da vida cotidiana. Passa ainda pela administração, gestão de serviços, planejamento, além das profissões tradicionais da atenção e do cuidado à pessoa, em sua visão integral.

A Saúde Mental relaciona-se, ainda, com os processos de organização social e comunitária, no exercício dos princípios da equidade, do acesso e da estruturação dos serviços públicos e privados. Pensar a Saúde Mental requer, portanto, uma revisão conceitual, colocando em cheque as práticas de 
fragmentação de conhecimentos e ações, o que obriga à busca de novas maneiras de pensar, compreender, significar e atuar.

Não há consciência de eu nem de mundo sem uma linguagem. O substrato do funcionamento da vida de relação se localiza na construção simbólica compartilhada (BECKER, 1971: 19-20). No momento atual, em que se elege a economia de mercado e o capitalismo neoliberal como ordenadores da vida, a linguagem que temos à disposição para orientar nossos modos de existir é a da fragmentação. Uma grande questão, para o campo da Saúde Mental, talvez seja, aonde nos leva esta linguagem, qual a compreensão de mundo e vida que ela promove? É importante fazer uma análise sobre como esta linguagem satisfaz as necessidades do ser humano e, aonde ela se revele inadequada ou incompetente, que outras formas de linguagem temos que explorar para podermos realmente nos aproximar de um real conhecimento sobre os fenômenos da psique.

\section{REFERÊNCIAS}

BARBOSA, Fernanda Elizabeth Sena; GUIMARÃES, Maria Beatriz Lisboa; SANTOS, Carlos Renato dos; BEZERRA, Adriana Falangola Benjamin; TESSER, Charles Dalcanale; SOUSA, Islandia Maria Carvalho de. Abangência territorial de pesquisas com interface em Práticas Integrativas e Complementares em Saúde na Estratégia de Saúde da Família do Brasil. Cad. Saúde Pública, 36 (6), 2020 • https://doi.org/10.1590/0102-311X00123420

BECKER, E. The birth and death of meaning. An interdisciplinary perspective on the problem of man. (2a. ed.). Nova Yorque: Free Press, 1971.

CAPES - Coordenação de Aperfeiçoamento de Pessoal de Nível Superior. Quarta semana da Avaliação Quadrienal terá análise de 12 áreas do conhecimento. Publicado em 25/07/2017. Atualizado em 28/07/2017. Disponível em https://www.gov.br/capes/pt-br/assuntos/noticias/quarta-semana-da-avaliacaoquadrienal-tera-analise-de-12-areas-do-conhecimento

CNPq - Conselho Nacional de Desenvolvimento Científico e Tecnológico. O CnPq e a divulgação científica. Publicado em 26/09/2013. Atualizado em 11/08/2021 Disponível em https://www.gov.br/cnpg/pt-br/assuntos/popularizacao-da-ciencia/ocnpq-e-a-divulgacao-cientifica 
FOUCAULT, Michel. A verdade e as formas jurídicas, In: Microfísica do poder, $24^{\mathrm{a}}$ ed. Rio de Janeiro: Graal, 2007,

HARRIS, Marvin. Cultural anthropology. New York: Harpern \& Row, 1990.

OLIVEIRA, Walter Ferreira de. A construção cultural da saúde e o espaço da medicina tradicional. Conferência de abertura apresentada no $2^{\circ}$ Simpósio Internacional de Disciplinas Etnobotânicas. La Paz, Bolívia, 16-18 de setembro de 2003.

PINEL, Philippe. Tratado médico-filosófico sobre a alienação mental ou a mania. Trad.: Joice Armani Galli. Porto Alegre: Editora da UFRGS; 2007. 272p. 